\title{
Myocardium T1 measurement using single and multi-shot SMART1Map acquisition: pros and cons
}

\author{
Pauline Ferry ${ }^{1,2^{*}}$, Anne Menini ${ }^{1,2}$, Glenn S Slavin ${ }^{3}$, Jeff A Stainsby ${ }^{4}$, Damien Mandry ${ }^{1,5}$, Laurent Bonnemains ${ }^{1,5}$, \\ Jacques Felblinger ${ }^{1,6}$, Marine Beaumont ${ }^{2,7}$
}

From 17th Annual SCMR Scientific Sessions

New Orleans, LA, USA. 16-19 January 2014

\section{Background}

The recently published method SMART1Map[1] has proposed a new true T1 measurement technique. It consists in a 2D saturation-recovery prepared balancedSSFP sequence which allows different acquisition schemes depending on the number of repetition (shot) used. Single-shot acquisition duration is short but cardiac motion blur can occur due to long acquisition window duration. Two-shot acquisition time allows an acquisition window twice smaller but inter acquisition window motion can occur. Note that single-shot scheme allows to acquire an additional point when magnetization has not yet undergo any saturation pulse, thus corresponding to an infinite saturation delay time $(T \infty)$. In this study, we compared both schemes on healthy volunteers to determine the most appropriate strategy for a large range of $\mathrm{T} 1$ values measurement at $3 \mathrm{~T}$.

\section{Methods}

Our study was carried out in 6 volunteers on a 3T MR scanner (GE, Signa HDxt) using SMART1Map on one mid-cavity short-axis, in end-diastole, in breath-hold. Single-shot (matrix $=128 * 224)$ and two-shot (matrix = $160 * 224)$ strategies leading to 5 time points ranging from $50 \mathrm{~ms}$ to $2966 \mathrm{~ms} \pm 473 \mathrm{~ms}$ were performed. We considered three data-sets: single-shot, two-shot and two-shot plus $\mathrm{T} \infty$ from single-shot. Breath-hold duration, chance of inter and/or intra acquisition motions, and spatial resolution were assessed for the different acquisition schemes. Post-processing $\mathrm{T} \infty$ was annotated with $9900 \mathrm{~ms}$ for fitting. For each data-set, pixel-wise
T1 maps were generated. Data were fitted using a 3parameter model. Due to sequence scheme, MR signal is likely to follow theoretical equation $S(t)=M 0-M 0(1-$ $\cos \theta) \exp (-\mathrm{t} / \mathrm{T} 1)$, usually modeled as $\mathrm{S}(\mathrm{t})=\mathrm{A}-\mathrm{B}^{*} \exp (-\mathrm{t} /$ $\mathrm{T} 1)$. On each T1 map, only the septum was encompassed for analysis, to overcome susceptibility or B1 effects on the lateral wall. For each ROI, average T1 with standard deviation were assessed. Data-set's mean T1 values with standard error of the mean $(n=6)$ were calculated; mean T1 standard deviations were also reported.

\section{Results}

Myocardium is better defined on the two-shot plus T $\infty$ data-set compared to others (Figure 1). Mean T1 value decreases when adding the To to the two-shot data-set (Figure 2).

\section{Conclusions}

Due to its long acquisition window, single-shot might lead to blurring limiting for focal $\mathrm{T} 1$ assessment. With a shorter acquisition window, two-shot acquisition is potentially more reliable, particularly when heart rate increases (shorter diastole period). However it suffers from poorly sampled recovery curves leading to noisy T1 maps. Adding T $\infty$, from single-shot acquisition, to two-shot data-set allowed to stabilize fitting and resulted in better agreement with previous studies (myocardium T1 range: from $1471 \pm 31 \mathrm{~ms}[2]$ to $1501 \pm 69 \mathrm{~ms}[3]$ ).

\section{Funding}

FEDER, Région Lorraine, France.

${ }^{1}$ IADI, Lorraine University, Vandoeuvre les Nancy, France

Full list of author information is available at the end of the article 


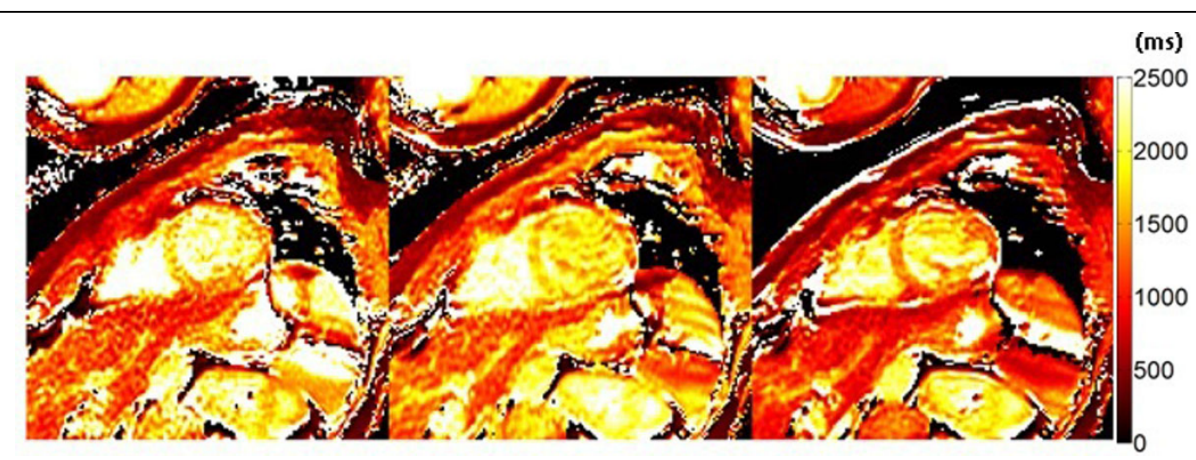

Figure 1 T1 maps. a, two-shot acquisition scheme. b, single-shot acquisition scheme. c, two-shot plus To scheme.

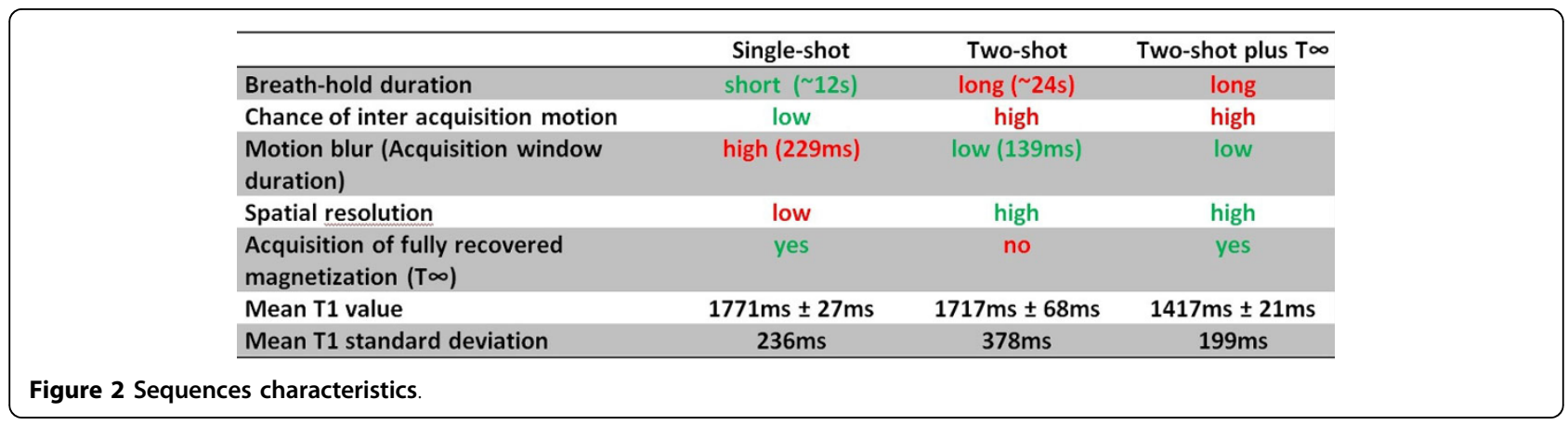

\section{Authors' details}

${ }^{1}$ IADI, Lorraine University, Vandoeuvre les Nancy, France. ${ }^{2}$ U947, Inserm,

Nancy, France. ${ }^{3} \mathrm{GE}$ Healthcare, Bethesda, Maryland, United States. ${ }^{4} \mathrm{GE}$

Healthcare, Toronto, Ontario, Canada. ${ }^{5} \mathrm{CHU}$, Nancy, France. ${ }^{6} \mathrm{CIT} 801$, Inserm,

Nancy, France. ${ }^{7} \mathrm{CIC}-\mathrm{IT}, \mathrm{CHU}$, Nancy, France.

Published: 16 January 2014

\section{References}

1. Slavin, Stainsby : JCMR 2012.

2. Stanisz: MRM 2005

3. Fitts: MRM 2012.

\section{doi:10.1186/1532-429X-16-S1-P69}

Cite this article as: Ferry et al:: Myocardium T1 measurement using

single and multi-shot SMART1Map acquisition: pros and cons. Journal of

Cardiovascular Magnetic Resonance 2014 16(Suppl 1):P69.

Submit your next manuscript to BioMed Central and take full advantage of:

- Convenient online submission

- Thorough peer review

- No space constraints or color figure charges

- Immediate publication on acceptance

- Inclusion in PubMed, CAS, Scopus and Google Scholar

- Research which is freely available for redistribution 